\title{
Transplantasyon Yapılan Çocukların Ebeveynlerinin Yaşam Kalitesi ve Bakım Yükü
}

\author{
Aynur AÇAR ${ }^{1}$ (iD) Hülya KARATAȘ ${ }^{2}$ iD Abdullah ÖZGÖNÜL ${ }^{3}$ \\ ${ }^{1}$ Harran Üniversitesi, Araştırma ve Uygulama Hastanesi, Şanlıurfa, Türkiye, acar.aynur@ hotmail.com \\ ${ }^{2}$ Harran Üniversitesi, Sağlık Bilimleri Fakültesi, Hemşirelik Bölümü, Şanlıurfa, Türkiye, hulya.karatas35@gmail.com \\ (Sorumlu Yazar/ Corresponding Author) \\ ${ }^{3}$ Harran Üniversitesi, Tıp Fakültesi, Genel Cerrahi ABD, Şanlıurfa, Türkiye, drozgonul@ yahoo.com

\begin{tabular}{|c|c|}
\hline Makale Bilgileri & ÖZ \\
\hline $\begin{array}{l}\text { Makale Geçmişi } \\
\text { Geliş: } 13.11 .2020\end{array}$ & $\begin{array}{l}\text { Amaç: } \mathrm{Bu} \text { çalışma, organ nakli yapılan çocukların ebeveynlerinin bakım yükü ve yaşam kalitesinin } \\
\text { belirlenmesi amacıyla yapılmıştır. }\end{array}$ \\
\hline Kabul: 13.02.2021 & Yöntem: Bu çalışma Şanlıurfa ilinde organ transplantasyon birimine başvuran çocuk hastaların ebeveynleri \\
\hline Yayın: 25.04.2021 & $\begin{array}{l}\text { ile tanımlayıcı olarak yapılmıştır. Şanlıurfa ilinde ikamet eden, dış merkezde transplantasyon yapılmış olan } \\
22 \text { çocuk hastanın ebeveyni çalışmanın örneklemini oluşturmuştur. Veriler Tanımlayıcı Özellikler Soru }\end{array}$ \\
\hline Anahtar Kelimeler: & Formu, Kısa Form SF-36 Yaşam Kalitesi Ölçeği ve Bakım Verme Yükü Ölçeği kullanılarak elde edilmiştir. \\
\hline $\begin{array}{l}\text { Transplantasyon, } \\
\text { Yaşam Kalitesi, }\end{array}$ & $\begin{array}{l}\text { Veriler SPSS } 22.0 \text { programında tanımlayıcı istatistikler, Mann Whitney } U \text { ve Kruskal Wallis testleri } \\
\text { kullanılarak değerlendirilmiştir. }\end{array}$ \\
\hline Bakım Yükü, & Bulgular: Çalışmaya alınan çocukların \%59.1'i erkek, \%36.4'ü 13-18 yaş aralığındadır. Çocukların \%91'ine \\
\hline Hemşirelik. & $\begin{array}{l}\text { karaciğer, \%4.5'ine kalp, \%4.5'ine böbrek nakli ve } \% 54.5 \text { 'ine canlı donörden nakil yapıldı̆̆ belirlenmiştir. } \\
\text { Ebeveynlerin Bakım Verme Yükü Ölçeği toplam puan ortalamalarına göre bakım yüklerinin } 27.32 \pm 8.35 \text { hafif- } \\
\text { orta düzeyde olduğu, yaşam kalitesi fiziksel ve mental sağlık puan ortalamalarının sırasıyla } 22.33 \pm 0.94 \text {, } \\
26.19 \pm 1.31 \text { olduğu belirlenmiştir. }\end{array}$ \\
\hline & $\begin{array}{l}\text { Sonuç ve Öneriler: Transplantasyon yapılan çocukların ebeveynlerinin yaşam kalitesi düşük, bakım yükleri } \\
\text { hafif/orta derecedir. Transplantasyon yapılan çocukların ebeveynlerinin yaşam kalitesinin ve bakım yükünün } \\
\text { izlenmesi önerilmektedir. }\end{array}$ \\
\hline
\end{tabular}

\section{Quality of Life and Care Burden of Organ Transplantated Children's Parents}

\begin{tabular}{|c|c|}
\hline Article Info & ABSTRACT \\
\hline $\begin{array}{l}\text { Article History } \\
\text { Received: } 13.11 .2020 \\
\text { Accepted: } 13.02 .2021 \\
\text { Published: } 25.04 .2021 \\
\text { Keywords: } \\
\text { Transplantation, } \\
\text { Quality of Life, } \\
\text { Caregiver Burden, } \\
\text { Nursing. }\end{array}$ & $\begin{array}{l}\text { Purpose: This study was carried out to determine the quality of life and burden of care of parents of } \\
\text { children undergone a transplantation procedure. } \\
\text { Method: This descriptive study was carried out with the parents of pediatric patients admitted to organ } \\
\text { transplantation unit in Sanliurfa province. Parents of } 22 \text { pediatric patients residing in Sanliurfa province and } \\
\text { had an organ transplant in an external centre constitute the sample of the study. The data were obtained using } \\
\text { the Descriptive Characteristics Questionnaire, Short Form-36 Quality of Life Scale, Caregiving Burden Scale. } \\
\text { The data were evaluated using descriptive statistics, Mann Whitney U and Kruskal Wallis tests. } \\
\text { Results:59.1\% of the children in the study were male } 36.4 \% \text { were between } 13-18 \text { years old. It was determined } \\
\text { that } 91 \% \text { of the transplanted organs in children was liver, } 4.5 \% \text { were the heart and ve } 4.5 \% \text { were kidney and } \\
\text { that } 54.5 \% \text { were transplanted from living donors. According to the total score averages of the parents obtained } \\
\text { in the Caregiving Burden Scale, it was determined that their burden of care was } 27.32 \pm 8.35 \text { mild to moderate, } \\
\text { and their quality of life, physical and mental health score averages were } 22.33 \pm 0.94,26.19 \pm 1.31 \text {, respectively. } \\
\text { Conclusion and Suggestions: The quality of life of the transplanted children's parents was found to be low } \\
\text { and the care burden was found to be mild/moderate. Monitoring the quality of life and burden of care of } \\
\text { parents of transplanted children is recommended. }\end{array}$ \\
\hline
\end{tabular}

Atıf/Citation: Açar, A. Karataş, H. \& Özgönül, A. (2021). Transplantasyon yapılan çocukların ebeveynlerinin yaşam kalitesi ve bakım yükü. Genel Să̆lık Bilimleri Dergisi, 3(1), 41-50.

"This article is licensed under a Creative Commons Attribution-NonCommercial 4.0 International License (CC BY-NC 4.0)" 


\section{GİRİ̧̧}

Organ transplantasyonu son dönem organ yetmezliği olan çocuklarda kabul gören bir tedavi yöntemidir. İleri cerrahi teknikler, kullanılan ilaçlar ve enfeksiyon kontrolüne yönelik gelişmeler sayesinde organ transplantasyonu yapılan çocukların hayatta kalma süreleri artmıştır (Ergün \& Sözbilen, 2012; Hwang ve ark., 2019; Sarwal \& Bagga, 2013; Törüner \& Büyükgönenç, 2012). Organ Transplantasyonu, organ yetmezliği sebebiyle yaşamını kaybetmek üzere olan hastaların yaşam sürelerini uzatarak nitelikli bir yaşam sağlamakta, hastalık sebebiyle gerçekleşen sağlık sorunlarını ortadan kaldırılarak yaşam kalitelerini yükseltmektedir (Sarwal \& Bagga, 2013).

Transplantasyon sürecinde olan bir çocuğun bakımında kararının verilmesi, çocuğun değerlendirilmesi, donör seçimi, transplantasyon sonrası çocuğun yoğun bakım süreci, enfeksiyonlardan korunması, tedavinin yapılması ile sağlıklı gelişiminin sürdürülmesi gerekmektedir (Ergün \& Sözbilen, 2012; Törüner \& Büyükgönenç, 2012). Transplantasyon süreci çocukları birçok yönden etkilemektedir. Yapılan bir çalışmada böbrek ve karaciğer transplantasyonu olan çocukların sağlıklı akranlarına oranla yaşam kalitesi puanlarının daha düşük olduğu, depresyon, dikkat eksikliği ve hiperaktivite insidansının arttığı, eğitimsel ve sosyal problemlerin yüksek oranda görüldüğü bildirilmiştir(Sarwal \& Bagga, 2013).

Transplantasyon süreci çocukla birlikte bakım veren ebeveynleride etkilenmektedir(Atagun ve ark., 2011; Doğan ve ark., n.d.; Sundaram ve ark., 2007). Birinci derecede bakım veren ebeveyn çocuğun tüm bakım sorumluluğunu almakta ve bakım sorumluluğu arttıkça çaresizlik, suçluluk, öfke, korku ve sosyal izolasyon gibi duygular yaşayabilmektedir (Atagun ve ark., 2011). Doğan ve arkadaşları tarafindan (2020) yapılan çalışmada; böbrek transplantasyonu olan çocukların ailelerinin psikolojik dayanıklılı̆̆ incelenmiş ve bakım verenlerin kendi gereksinimleriyle minimum düzeyde ilgili oldukları belirlenmiştir. Çocuklara bakım verenlerin \%79.2'sinin kadın olduğu, psikolojik dayanıklılık ölçeği gelecek algısına yönelik altboyut puan ortalamasının en düşük olduğu saptanmıştır (Doğan ve ark., n.d.)

Bakım yükü kavramı bakım yapanın, kronik hastalığı olan kişiye bakım verme sürecinde, güçlük yaşaması, kendini yük altında hissetmesi olarak açıklanmaktadır. Başka bir ifadeyle bakım veren yükü, bakım sunarken yaşanabilen fiziksel, psikolojik, sosyal veya finansal tepkileri ifade etmede kullanılmaktadır (Atagun ve ark., 2011; Beyazıt, 2017) (Demiral, 2016). Ebeveynlerinin bakım yükünün belirlenmesine yönelik literatürde çalışmalar bulunmaktadır. Bu çalışmalar fiziksel/zihinsel engelli ve kanser tanısı almış çocukların ebeveynleriyle yapılmış çalışmalardır(Aksu, 2014; Beyazıt, 2017; Coşkun, 2013; Karahan \& Islam, 2013; Kardaş Özdemir ve ark., 2009; Metin Karaaslan \& Çelebioğlu, 2020). Literatür incelendiğinde organ nakli yapılan çocukların ve ailelerinin yaşam kalitesi ve bakım yükü ile ilgili sınırlı sayıda çalışma bulunmakta olup, bazı çalışmalarda çocuk ve ebeveynlerin yaşam kalitesi düşük (Dew ve ark., 2009; Dobbels ve ark., 2010; Haavisto ve ark., 2013; Karayurt ve ark., 2015; Kärrfelt ve ark., 2000) bazı çalışmalarda ise (Altuğ, 2011; Baran ve ark., 2011; Sundaram ve ark., 2007) yaşam kalitesi yüksek bulunmuştur.

$\mathrm{Bu}$ çalışma; transplantasyon yapılmış çocukların ebeveynlerinin yaşam kalitesi ve bakım yükünün belirlenmesi amacıyla planlanmıştır.

\section{YÖNTEM}

\section{Çalışmanın Modeli}

Bu çalışma Türkiye'nin güneydoğusunda bir ilde üniversite hastanesinin transplantasyon birimine başvuran çocukların ebeveynleri ile tanımlayıcı olarak yapılmıştır.

\section{Örneklem}

Çalışmanın yapıldığı transplantasyon birimi 2013 yılından itibaren hizmet vermekte olup bu merkezde sadece yetişkinlere transplantasyon yapılmakta, çocuk hastaların transplantasyonun yapıldı̆̆ merkezde izlenmeleri için sevk işlemleri ve bazı kontrolleri yapılmaktadır. Birim ilde transplantasyonlu hastaların işlemlerinin yapıldığ tek sağlık merkezidir. Bu nedenle çalışmada örneklem seçimine gidilmemiş kayıtlı tüm çocuk hastalara ulaşılmaya 
çalışılmıştır. Şanlıurfa ilinde ikamet eden, dış merkezde transplantasyon yapılmış olan 22 çocuğun 22 ebeveynleri $(\mathrm{n}=22)$ çalışmanın örneklemini oluşturmuştur.

\section{Veri Toplama Araçları}

Veriler, Tanımlayıcı Özellikler Soru Formu, SF-36 Yaşam Kalitesi Ölçeği Kısa Form ve Bakım Verme Yükü Ölçeği kullanılarak elde edilmiştir.

Tanımlayıcı Özellikler Soru Formu: iki bölümden oluşmaktadır. Birinci bölümde çocuğa ve ebeveynine ilişkin demografik bilgiler, ikinci bölümde ise uzman görüşü alınarak hazırlanan transplantasyona ilişkin sorular (transplantasyon süresi, transplantasyon yapılan organ vs) olmak üzere toplam 17 sorudan oluşmaktadır. Transplantasyona ilişkin soru formuna; çocuk sağlığ 1 ve hastalıkları, genel cerrahi, çocuk sağlığı ve hastalıkları hemşireliği ve cerrahi hastalıklar hemşireliğinden transplantasyon konusunda çalışan öğretim üyeleri ve çocuk cerrahi servisinde çalışan hemşirelerden görüş alınarak hazırlanmıştır. Uzmanlardan formda sorulan transplantasyona ilişkin soruların uygunluk durumunu değerlendirmeleri istenmiştir.

SF-36 Yaşam Kalitesi Ölçeği Kısa Form: Ölçek Ware tarafından 1992 yllında geliştirilmiştir. Koçyiğit tarafindan Türkçe geçerlik güvenirliği yapılmıştır. Ölçek 36 madde ve 8 altboyuttan oluşmaktadır. Altboyutlar mental sağlık (5 madde), fiziksel fonksiyon (10 madde), fiziksel sorunlara bağlı rol kısıtlılıkları (4 madde), sosyal fonksiyon (2 madde), ağrı (2 madde), emosyonel sorunlara bağlı rol kısıtlılıkları (3 madde), enerji/vitalite (4 madde), ve sağlığın genel algılanmasıdır (5 madde). SF-36 yaşam kalitesi ölçeğinin alt ölçeklerini içeren soruların aldıkları ağırlıklı puanlar toplanarak mental sağlık ve fiziksel sağlık özet değer elde edilmektedir. Ölçeğin toplam puanı bulunmamaktadır. Elde edilen özet değerler sıfır ile yüz arasında değişen sürekli değişken olarak ifade edilmektedir; "0" kötü sağlığ1, "100” iyilik durumunu göstermektedir (Koçyiğit, 1999).

Bakım Verme Yükü Ölçeği: Zarit, Reever ve Bach-Peterson tarafindan 1980 y1lında geliştirilen ölçek İnci ve Erdem (2008) tarafından Türkçeye çevrilerek geçerlik güvenirlik çalışması yapılmıştır. Ölçek hastaya bakım vermenin kişinin yaşamı üzerine olan etkisini belirleyen 22 maddeden oluşan 4'lü Likert tipinde bir ölçektir. Ölçeğin min-max puanı 0-88 olarak belirtilmekte, 0-20 puan az/hiç yük olmaması, 21-40 puan hafif/orta derecede yük, 41-60 puan orta/ileri derecede yük ve 61-88 puan aşırı yük olması şeklinde değerlendirilmektedir. Puan artış1 yaşanan sıkıntının yüksek olduğunu göstermektedir. Ölçeğin iç tutarlılık katsayısı 0.95 olarak bildirilmiştir (İnci \& Erdem, 2010).

\section{Verilerin Toplanması}

Veri toplama formları hastanenin transplantasyon polikliniğinde, muayene sonrasında, çocuğu muayeneye getiren ebeveyn yüz yüze görüşülerek araştırmacı tarafından doldurulmuştur. Formlar doldurulmadan önce ebeveynlere çalışma hakkında bilgi verilmiş, yazılı onamları alınmış ve çalışmaya katılmayı kabul edenlere veri toplama formları uygulanmıştır. Veri toplama süresi yaklaşık $20 \mathrm{dk}$ sürmüştür.

\section{Verilerin Analizi}

Verilerin değerlendirilmesinde SPSS 22.0 paket programı kullanılmıştır. Verilerin analizinde tanımlayıcı istatistikler, Mann Whitney U ve Kruskal Wallis testleri kullanılmıştır. Bu çalışmada bağımlı değişken ebeveynin yaşam kalitesi ve bakım yükü ölçeği puan ortalamasıdır. Bağımsız değişkenlere göre (çocuğun yaşı, cinsiyeti, annenin yaşı, çocuk sayısı, gelir durumu, donör, nakil şekli, transplantasyon sonrası geçen süre) yaşam kalitesi ve bakım yükü ölçeği puan ortalamaları arasındaki farkı belirlemek için iki değişkende Mann Whitney U testi, üç ve üzeri değişkende Kruskal Wallis testi kullanılmıştır.

\section{Etik}

Araştırmanın uygulanabilmesi için üniversite hastanesinin Etik Kurul'undan (18/10/2016 tarih ve 34271 sayı11) ve çalışmanın yapılacağı kurumdan yazılı izin ve çalışmaya katılan ebeveynlerden sözel izin alınmıştır. 


\section{BULGULAR}

Çalışmaya alınan çocukların \%59.1'i erkek, \%4.5'i 0-3 yaş, \%27.3'ü 4-6 yaş, \%31.8'i 7-12 yaş ve \%36.4'ü 13-18 yaş aralığındadır. Çocukların \%91'ine karaciğer, \%4.5'ine kalp, \%4.5'ine böbrek nakli ve \%54.5'ine canlı donörden nakil yapıldığı, \%77.3'ünün transplantasyon sonrası 1-5 yıl geçtiği belirlenmiştir. Annelerin \%63.6'sı 2039 yaş aralığında, \%36.4'ü 40 ve üstü yaştadır. Annelerin \%63.6'sı, babaların \%9.1'i okuryazar değil, \%77.3'ü dört ve daha fazla çocuğa sahip ve $\% 40.9$ 'u orta düzeyde geliri bulunmaktadır.

Çalışmada her iki ebeveyni ile muayeneye gelen çocukların anneleri tarafından sorular yanıtlanmış, çalışmaya ilişkin verilerin \% 100.0'ü annelerden alınmıştır.

Transplantasyon olan çocukların ebeveynlerinin bakım yükü incelendiğinde; Bakım Verme Yükü Ölçeği (BYÖ) puan ortalaması $27.32 \pm 8.35$ olarak saptanmıştır (Tablo 1). Bakım verenlerin BYÖ'den aldıkları ölçek puan ortalamalarına göre bakım verenlerin bakım yükü durumları incelendiğinde; \%77.3'ü hafif-orta derecede bakım yüküne, \%4.5'i orta-ileri derecede bakım yükü olduğu saptanmıştır.

Ebeveynlerin yaşam kalitesi ölçeğinin fiziksel sağlık skoru toplam puan ortalaması $22.33 \pm 0.94$, mental sağl1k skoru toplam puan ortalamas $26.19 \pm 1.31$ olarak bulunmuştur. Ailelerin yaşam kalitesi ölçeğinden, en düşük mental rol alt boyutundan $4.77 \pm 1.50$, en yüksek fiziksel işlev alt boyutundan $25.90 \pm 4.78$ puan aldıkları saptanmıştır (Tablo 1).

Tablo 1. Bakım Verme Yükü Ölçeği ve Yaşam Kalitesi Ölçeğinin Alt Boyutları Puan Ortalamalarının Dă̆llımı

\begin{tabular}{llll}
\hline Ölçek & Min & Max & $\mathbf{X} \pm \mathbf{S d}$ \\
\hline BYÖ* & 14.00 & 46.00 & $27.32 \pm 8.35$ \\
SF-36 & & & \\
Fiziksel İşlev & 12.00 & 30.00 & $25.90 \pm 4.78$ \\
Fiziksel Rol & 4.00 & 8.00 & $6.31 \pm 1.98$ \\
Ağrı & 4.20 & 11.00 & $8.60 \pm 2.18$ \\
Genel Sağlık & 11.00 & 21.40 & $15.40 \pm 3.47$ \\
Yaşamsallık & 9.00 & 20.00 & $13.95 \pm 2.73$ \\
Sosyal İşlev & 5.00 & 10.00 & $7.72 \pm 1.98$ \\
Mental Rol & 3.00 & 6.00 & $4.77 \pm 1.50$ \\
Mental Sağlık & 16.00 & 23.00 & $19.18 \pm 2.34$ \\
Fiziksel Sağlık Skoru & $\mathbf{2 0 . 7 8}$ & $\mathbf{2 4 . 8 3}$ & $\mathbf{2 2 . 3 3} \pm \mathbf{0 . 9 4}$ \\
Mental Sağlık Skoru & $\mathbf{2 3 . 3 3}$ & $\mathbf{2 8 . 0 7}$ & $\mathbf{2 6 . 1 9 \pm 1 . 3 1}$ \\
\hline
\end{tabular}

*BYÖ (Bakım Verme Yükü Ölçeği)

Tanımlayıcı özelliklere göre ebeveynin bakım yükü ölçeği puan ortalamaları arasındaki farkın belirlenmesine yönelik yapılan analizde; çocuğun cinsiyeti, yaşı, annenin yaşı, çocuk sayısı, gelir durumu, donör, transplantasyon şekli ve nakil sonrası süresi ile bakım yükü puan ortalaması arasında istatistiksel açıdan anlamlı bir farklılık bulunmamıştır (Tablo 2, $\mathrm{p}>0.05$ ).

Tablo 2. Tanımlayıcı Özelliklere Göre Ebeveynlerin Bakım Verme Yükü Ölçeği Puan Ortalamalarının Karşılaştırılması

\begin{tabular}{lllll}
\hline Tanımlayıcı Özellikler & $\mathbf{n}$ & $\mathbf{X}$ & $\mathbf{U}$ & $\mathbf{p}$ \\
\hline Cocuğun Cinsiyeti & 9 & & & \\
Kız & 13 & 14.17 & 34.50 & 0.108 \\
Erkek & 12 & 9.65 & & \\
Donör & 10 & 9.92 & 41.00 & 0.209 \\
$\begin{array}{l}\text { Canlı } \\
\text { Kadavra } \\
\text { Transplantasyon Şekli }\end{array}$ & 10.40 & & \\
Elektif & 12 & 13.40 & 41.00 & 0.209 \\
$\begin{array}{l}\text { Acil } \\
\text { Nakil Sonrası Süre }\end{array}$ & 12 & 9.92 & & \\
$1-5$ yıl & 17 & 11.21 & 37.50 & 0.694 \\
$6-10$ yıl & 5 & 12.50 & & \\
\hline
\end{tabular}




\begin{tabular}{|c|c|c|c|c|}
\hline \multicolumn{5}{|l|}{ Annenin Yaşı } \\
\hline 20-39 yaş & 14 & 12.57 & 41.00 & 0.305 \\
\hline 40 ve üstü yaş & 8 & 9.63 & & \\
\hline Çocuğun Yaşı & $\mathbf{n}$ & $\mathbf{X}$ & KW & $\mathbf{p}$ \\
\hline $0-3$ yaş & 1 & 6.50 & 5.002 & 0.172 \\
\hline 4-6 yaş & 6 & 13.00 & & \\
\hline $7-12$ yaş & 7 & 9.21 & & \\
\hline $13-18$ yaş & 8 & 10.50 & & \\
\hline \multicolumn{5}{|c|}{ Ailedeki Çocuk Sayısı } \\
\hline Tek Çocuğa Sahip & 1 & 6.50 & 0.812 & 0.666 \\
\hline $2-3$ & 4 & 13.00 & & \\
\hline 4 ve üstü & 17 & 11.44 & & \\
\hline \multicolumn{5}{|l|}{ Aylık Gelir Düzeyi } \\
\hline Kötü & 6 & 11.5 & 0.660 & 0.719 \\
\hline Orta & 9 & 10.44 & & \\
\hline İyi & 7 & 13.07 & & \\
\hline
\end{tabular}

Tablo 3. Tanımlayıcı Özelliklere Göre SF-36 Yaşam Kalitesi Ölçeğinin Puan Ortalamalarının Karşılaştırılması

\begin{tabular}{|c|c|c|c|c|}
\hline Demografik Özellikler & Fiziksel Sağlık Skoru & Test & Mental Sağlık Skoru & Test \\
\hline \multicolumn{5}{|l|}{ Cinsiyet } \\
\hline $\mathrm{K} 1 \mathrm{z}$ & 14.33 & $\mathrm{U}=33.0$ & 7.00 & \multirow{2}{*}{$\begin{array}{l}U=34.0 \\
\mathbf{p}=\mathbf{0 . 0 0 7}\end{array}$} \\
\hline Erkek & 9.54 & $\mathrm{p}=0.089$ & 14.62 & \\
\hline \multicolumn{5}{|l|}{ Donör } \\
\hline Canlı & 12.25 & $\mathrm{U}=51.0$ & 10.17 & \multirow{2}{*}{$\begin{array}{l}\mathrm{U}=44.0 \\
\mathrm{p}=0.291\end{array}$} \\
\hline Kadavra & 10.60 & $\mathrm{p}=0.553$ & 13.10 & \\
\hline \multicolumn{5}{|l|}{ Nakil şekli } \\
\hline Elektif & 10.60 & $\mathrm{U}=51.0$ & 13.10 & \multirow{2}{*}{$\begin{array}{l}\mathrm{U}=44.0 \\
\mathrm{p}=0.291\end{array}$} \\
\hline Acil & 12.25 & $\mathrm{p}=0.553$ & 10.17 & \\
\hline \multicolumn{5}{|l|}{ Nakil Sonrası Süre } \\
\hline $1-5$ y1l & 10.94 & $\mathrm{U}=33.00$ & 12.59 & \multirow{2}{*}{$\begin{array}{l}U=24.00 \\
p=0.147\end{array}$} \\
\hline $6-10 y_{11}$ & 13.40 & $\mathrm{p}=0.457$ & 7.80 & \\
\hline \multicolumn{5}{|l|}{ Annenin Yaşı } \\
\hline $20-39$ yaş & 12.29 & $\mathrm{U}=45.00$ & 10.07 & \multirow{2}{*}{$\begin{array}{l}U=36.00 \\
p=0.172\end{array}$} \\
\hline 40 ve üzeri yaş & 10.13 & $\mathrm{p}=0.453$ & 14.00 & \\
\hline \multicolumn{5}{|l|}{ Çocuğun Yaşı } \\
\hline $0-3$ yaş & 21.00 & $\mathrm{KW}=6.023$ & 4.00 & \multirow{4}{*}{$\begin{array}{l}\mathrm{KW}=2.949 \\
\mathrm{p}=0.400\end{array}$} \\
\hline $4-6$ yaş & 6.83 & $\mathrm{p}=0.111$ & 14.00 & \\
\hline $7-12$ yaş & 11.86 & & 9.57 & \\
\hline $13-18$ yaş & 13.50 & & 12.25 & \\
\hline \multicolumn{5}{|l|}{ Ailedeki Çocuk Sayısı } \\
\hline Tek çocuk & 21.00 & $\mathrm{KW}=2.413$ & 4.00 & \multirow{3}{*}{$\begin{array}{l}\mathrm{KW}=1.701 \\
\mathrm{p}=0.427\end{array}$} \\
\hline $2-3$ & 12.25 & $\mathrm{p}=0.299$ & 10.25 & \\
\hline 4 ve üstü & 10.76 & & 12.24 & \\
\hline \multicolumn{5}{|l|}{ Gelir Düzeyi* } \\
\hline Kötü & 7.33 & $\mathrm{KW}=9.145$ & 17.33 & \multirow{3}{*}{$\begin{array}{l}\mathrm{KW}=8.655 \\
\mathbf{p}=\mathbf{0 . 0 1 3}\end{array}$} \\
\hline Orta & 9.22 & $p=0.010$ & 11.33 & \\
\hline İyi & 17.57 & & 6.71 & \\
\hline
\end{tabular}

*Gelir düzeyi ebeveynin kendi ifadesidir.

Tanımlayıcı özelliklere göre ebeveynin yaşam kalitesi ölçeği puan ortalamaları arasındaki farkın belirlenmesine yönelik yapılan analizde; çocuğun yaşı, annenin yaşı, çocuk sayısı, donör, transplantasyon şekli ve nakil sonrası süresi ile yaşam kalitesi ölçeği fiziksel ve mental sağlık özet puan ortalamaları arasında istatistiksel olarak anlamlı bir fark bulunmamıştır (Tablo 3, p>0.05). Çocuğun cinsiyeti ile mental sağlık özet puanı, gelir düzeyi ile mental ve fiziksel sağlık özet puanları arasında istatistiksel olarak anlamlı bir fark saptanmıştır (Tablo 3, $\mathrm{p}<0.05)$. 


\section{TARTIŞMA}

Literatürde pediatrik organ nakilli alıcıların ve ailelerinin yaşam kalitesi ve bakım yükü ile ilgili sınırlı sayıda çalışma bulunmaktadır. Kronik hastalığa sahip çocukların ebeveynlerinin bakım yükünün belirlenmesine yönelik yapılan bazı çalışmalarda (Altuğ, 2011; Kardaş Özdemir ve ark., 2009; Koçak ve ark., 2010), bakım yükü puanı hafif ve orta dereceli olarak bulunurken, bazı çalışmalarda (Coşkun, 2013; İnci \& Erdem, 2010) ise yüksek bulunmuştur. Organ nakli sürecinin karmaşık bir süreç olması, ailenin sürecin her aşamasına desteklenmesi gerekliliğinin bakım yükü puanını etkilediği düşünülmektedir. Bizim çalışmamızda ise literatürle uyumlu olarak transplantasyon yapılan çocukların ebeveynlerinin bakım verme yükü ölçeği puan ortalaması $27.32 \pm 8.35$ hafif ve orta dereceli olarak saptanmıştır (Tablo 2).

Özdemir ve ark (2009) kanserli çocukların ailelerinin bakım yüküne bakıldığında annenin yaşı, eğitim düzeyi, çocuk sahibi olma durumu ile bakım yükü puanları arasında anlamlı bir farklılık saptanmazken, ailenin gelir durumuna göre bakım yükü arasındaki fark istatistiksel olarak anlamlı saptanmıştır (Kardaş Özdemir ve ark., 2009). Erdem ve arkadaşları (2013) kronik hastalığı olan çocukların ailelerinin bakım yükünüü inceledikleri çalışmalarında, ailelerin bakım yükü puan ortalamaları ile annenin yaşı, eğitim durumu ve ev işlerinde destek alma durumunun arasında anlamlı fark saptanmamıştır (Erdem ve ark., 2013). Karahan ve ark (2013) yaptığı çalışmada cinsiyetin farkı saptanmamışken, hastaların yaş ortalamasında anlamlı fark saptanmıştır (Karahan \& Islam, 2013). Araştırmamızda organ transplantasyonu olan çocukları ebeveynlerin tanımlayıcı özellikleri ile bakım verme yükü ölçeği puan ortalaması karşılaştırıldığında çocukların cinsiyeti, yaşları, donör, nakil şekli, nakil süresi, annenin yaşı, gelir düzeyi arasında istatistiksel olarak anlamlı bir farklılık saptanmamış olup, literatürle uyumlu sonuçlar elde edilmiştir (Tablo 3).

Organ transplantasyonu olan çocukların ve ailelerin yaşam kalitesinin incelendiği çalışmalarda farklı sonuçlar elde edilmiştir. Yapılan bazı çalışmalarda yaşam kalitesi (Dalvand ve ark., 2017; Dolgun ve ark., 2013) fiziksel ve mental sağlık skor ortalamaları yüksek bulunurken bazı çalışmalarda (Dehghani ve ark., 2012; Haavisto ve ark., 2013) düşük bulunmuştur. Çalışmamızda transplantasyon yapılan çocukların ebeveynlerinin yaşam kalitesi fiziksel sağlık skoru toplam puan ortalaması $22.33 \pm 0.94$ mental sağlık skoru toplam puan ortalaması $26.19 \pm 1.31$ olarak düşük düzeyde olduğu saptanmıştır (Tablo 2). Altuğ (2011) Karaciğer nakli olan çocukların ve ailelerinin yaşam kalitelerini, süreçlerini etkileyen değişkenleri belirlemek amacıyla yaptığı çalışmada; son dönem karaciğer yetmezliği olan çocuklara uygulanabilecek tek tedavi seçeneği olan karaciğer naklinin, sadece çocuğun hayatını kurtarmakla kalmayıp çocuk ve ailenin yaşam kalitesini olumlu yönde etkilediği bildirilmektedir (Altuğ, 2011). Sundaram ve ark (2007) karaciğer ve böbrek nakli olan ergenlerin ve bakım verenlerin yaşam kalitesini incelendiğinde nakil hastalarının fiziksel ve psikolojik işlevleri yüksek bulunurken bakım verenlerin fiziksel sağlıktan çok psikolojik sağlığının bozuk olduğu belirlenmiştir (Sundaram ve ark., 2007).

Dehghani ve ark. (2012) karaciğer nakli olan çocuk ve ailenin yaşam kalitesine bakıldığında nakil olan ve olmayan çocuklar karşılaştıııldığında yaşam kalitesi anlamlı olarak düşük bulunmuştur (Dehghani ve ark., 2012). Haavisto ve ark. (2013) çocuklarda kalp, böbrek, karaciğer nakli sonrası yaşam kalitesini değerlendirdikleri çalışmada nakilli çocukların sağlıklı akranlarına göre daha kötü yaşam kalitesine sahip olduğu saptanmıştır (Haavisto ve ark., 2013). Gritti ve ark (2013) karaciğer nakli yapılan çocukların uzun vadeli sağ kalımında ve klinik olarak stabil kronik karaciğer hastalığı olan çocukların sağlıklı yaşam kalitesi karşılaştırılmıştır (Gritti ve ark., 2013). Çocukların genel sağlık durumunun kötü olduğu belirlenmiştir. Karayurt ve ark (2015) yaptığı çalışmada; 1996-2004 yılları arasında karaciğer transplantasyonu yapılan 0-18 yaş grubu 27 çocuk hastada okul başarısı, depresyon, tedaviye uyum, ilaç uyumu ve semptom deneyimleri incelenmiştir. Çocukların \%44.4'ünün 20 ve daha fazla gün okula gidemediği, anksiyete, sinirlilik, yorgunluk ve konsantrasyonda güçlük yaşadı̆̆ı, immünsupresif tedavinin yan etkileriyle ilgili kliniğe başvurunun yüksek olduğu, \%11'inin depresyon belirtileri gösterdiği saptanmıştır (Karayurt ve ark., 2015).

Dobbles ve ark (2010) tarafından yapılan çalışmada; 23 böbrek transplantasyonu yapılmış adölesanın depresyon, semptom deneyimi ve tedaviye uyum ve sağlıkla ilgili yaşam kalitesi incelenmiştir (Dobbels ve ark., 2010). Adölesanların \%17.4'ünde depresyon görüldügüu, sigara içme, yasa dışı ilaç kullanma, diyete uymama ve 
egzersiz düzeyinde azalma olduğu tespit edilmiştir. Adölesanlarda görülen semptomlar incelenmiş ve en yüksek oranda iştahsızlık, yorgunluk, başağrısı, saçlarda dökülme, el ayaklarda siğiller görüldüğü bildirilmiş̧tir. Tyhs ve ark. (2015) 23 çalışmanın incelendiği sistematik derleme çalışmasında; canlıdan böbrek ve karaciğer nakli yapılan çocukların, vericilerin ve ailelerin psikososyal sorunları incelenmiştir. Alıcıların başetme yeteneklerini ve akran ilişkilerini geliştirdiği ancak anksiyete, depresif semptomlara neden olduğu bildirilmiştir (Thys ve ark., 2015).

Dew ve ark (2009) yapılan meta analizde 61 çalışmada organ nakli yapılan çocukların yaşadıkları sorunlar incelenmiştir. Düşük sosyoekonomik durum, ebeveynlerin ayrı olması, çocukta psikiyatrik bozukluk olması, yetersiz aile bağlarının ve desteğinin olması, çocuğun yaşının artması tedaviye uyumsuzluğu önemli oranda arttırdığı belirlenmiştir (Dew ve ark., 2009). Haberal ve ark (2000) Türkiye de böbrek nakli olan 56 çocuğun ileriki yaşantısı incelenmiş ve hastaların \%56'sının eğitimlerine devam edemediği belirlenmiştir (Haberal ve ark., 2000). Baran ve ark (2011) tarafından 80 çocuğun karaciğer naklinden sonraki büyüme ve gelişimine bakılmıştır. Büyüme ve gelişmeye 6 ay ve 1,2,3,4 ve 5 yıl sonrasında bakılmıştır. Karaciğer naklinden sonra ilk 6 ayda büyüme hızlı bir artış gösterirken ilerleyen yıllarda yavaşlamaya geçmiştir (Baran ve ark., 2011).

\section{SONUÇ ve ÖNERILER}

Çalışmamızda transplantasyon yapılmış çocukların ebeveynlerinin yaşam kalitesi düşük, bakım yükleri hafif/orta derecedir. Transplantasyon yapılan çocukların ebeveynlerinin yaşam kalitesinin ve bakım yükünün izlenmesi, ebeveynlerin ve çocukların güçlendirilmesine yönelik çalışmaların yapılması önerilmektedir.

\section{Finansal destek}

Finansal destek alınmamıştır.

\section{Çıkar çatıșması}

Çıkar çatışması bulunmamaktadır.

Yazar Katkıları: Tasarım/Design: A.A., H.K., A.O.; Veri Toplama veya Veri Girişi Yapma/Data Collection or Processing: A.A., A.O.; Analiz ve Yorum/Analysis or Interpretation: A.A., H.K.; Literatür Tarama/ Literature Search: A.A, H.K.; Yazma/Writing: A.A., H.K., A.O.

\section{KAYNAKLAR}

Aksu, A. (2014). Kanser tanısı konmuş çocuk yakınlarının bakım yüklerinin belirlenmesi. Sağlık Bilimleri Enstitüsü. http://dergipark.gov.tr/sagakaderg

Altuğ, N. (2011). Karaciğer nakilli çocukların ve ailelerinin yaşam kalitesi/yaşam kalitesini etkileyen değişkenlerinin belirlenmesi. Yayınlanmamış Yüksek Lisans Tezi. Ege Üniversitesi Sağlık Bilimleri Enstitüsü. İzmir https://tez.yok.gov.tr/UlusalTezMerkezi.

Atagun, M., Balaban, O., Atagun, Z., Elagoz, M., \& Ozpolat, A. (2011). Caregiver Burden in Chronic Diseases. Psikiyatride Guncel Yaklasimlar - Current Approaches in Psychiatry, 513. https://doi.org/10.5455/cap.20110323

Baran, M., Cakir, M., Unal, F., Tumgor, G., Yuksekkaya, H. A., Arikan, C., Kilic, M., \& Aydogdu, S. (2011). Evaluation of Growth After Liver Transplantation in Turkish Children. Digestive Diseases and Sciences, 56(11), 3343-3349. https://doi.org/10.1007/s10620-011-1727-6

Beyazıt, U., Taşçığlu, G. Ayhan, A.B. (2017). Hastanede Tedavi Gören Çocukların Ebeveynlerinde Bakım Verme Yükünün İncelenmesi. Adnan Menderes Üniversitesi Sağllk Bilimleri Fakültesi Dergisi, 1(1), 10-19. https://dergipark.org.tr/tr/pub/amusbfd/issue/30708/334614

Coşkun, D. (2013). Fiziksel engelli çocuğu olan ebeveynlerde bakım yükünün ve aile işlevlerinin değerlendirilmesi (Yayımlanmamış doktora tezi). Ataü̈rk Üniversitesi, Sağllk Bilimleri Enstitüsü, Erzurum. http://earsiv.atauni.edu.tr/xmlui/handle/123456789/1298.

Dalvand, H., Dehghan, L., Hosseini, seyed ali, Feizi, A., \& Kalantri, M. (2017). Comparison of Health-Related Quality of Life in Mothers of Children with Spina Bifida and Cerebral Palsy. International Journal of Pediatrics, 5, 5677-5685. https://doi.org/10.22038/ijp.2017.23670.2000

Dehghani, S. M., Imanieh, M. H., Honar, N., Haghighat, M., Astaneh, B., Bahador, A., \& Malek-Hosseini, S. A. (2012). Evaluation of quality of life in children six months after liver transplantation. Middle East Journal of Digestive Diseases, 4(3), 158-162. http://www.ncbi.nlm.nih.gov/pubmed/24829650 
Demiral, B. (2016). Serebral palsili çocukların annelerinin ortopedik girişim öncesi ve sonrası bakım yükünün belirlenmesi. [Yüksek Lisans Tezi, Bahçeşehir Üniversitesi Sağlık Bilimleri Enstitüsü] https://tez.yok.gov.tr/UlusalTezMerkezi/tezSorguSonucYeni.jsp

Dew, M. A., Dabbs, A. D., Myaskovsky, L., Shyu, S., Shellmer, D. A., DiMartini, A. F., Steel, J., Unruh, M., Switzer, G. E., Shapiro, R., \& Greenhouse, J. B. (2009). Meta-Analysis of Medical Regimen Adherence Outcomes in Pediatric Solid Organ Transplantation. Transplantation, 88(5), 736-746. https://doi.org/10.1097/TP.0b013e3181b2a0e0

Dobbels, F., Decorte, A., Roskams, A., \& Van Damme-Lombaerts, R. (2010). Health-related quality of life, treatment adherence, symptom experience and depression in adolescent renal transplant patients. Pediatric Transplantation, 14(2), 216-223. https://doi.org/10.1111/j.1399-3046.2009.01197.x

Doğan, S., Çelik, E., Öztürk, K., \& Aydemir, S. (n.d.). Çocukları Böbrek Transplantasyonu Olan Ailelerin Psikolojik Dayanıklılı̆̆1. Nefroloji Hemşireliği Dergisi, 15(3), 240-250. https://doi.org/10.47565/ndthdt.2020.21

Dolgun, E., Yavuz, M., Çelik, A., \& Ergün, M. O. (2013). The effects of constipation on the quality of life of children and mothers. Turk J Pediatr, 55(2), 180-185. https://www.researchgate.net/publication/258314219

Erdem, E., Korkmaz, Z., Tosun, Ö., Özlem, A., Nevin, Us., \& Bayat, M. (2013). Kronik Hastalığı Olan Çocukların Annelerinin Bakım Yükü. Sağlık Bilimleri Dergisi, 22(2), 150-157. https://dergipark.org.tr/tr/pub/eujhs/issue/44558/552829

Ergün, O., \& Sözbilen, M. (2012). Pediatric liver transplantation. Turkish Association of Pediatric Surgeons, 4-19. https://doi.org/10.5222/JTAPS.2012.004

Gritti, A., Pisano, S., Salvati, T., Di Cosmo, N., Iorio, R., \& Vajro, P. (2013). Health-related quality of life in pediatric liver transplanted patients compared with a chronic liver disease group. Italian Journal of Pediatrics, 39(1), 55. https://doi.org/10.1186/1824-7288-39-55

Haavisto, A., Korkman, M., Sintonen, H., Holmberg, C., Jalanko, H., Lipsanen, J., \& Qvist, E. (2013). Risk factors for impaired quality of life and psychosocial adjustment after pediatric heart, kidney, and liver transplantation. Pediatric Transplantation, 17(3), 256-265. https://doi.org/10.1111/petr.12054

Haberal, M., Bereket, G., Karakayalı, H., Arslan, G., Moray, G., \& Bilgin, N. (2000). Pediatric renal transplantation in Turkey:A review of 56 cases from a single center. Pediatric Transplantation, 4(4), 293-299. https://doi.org/10.1034/j.1399-3046.2000.00130.x

Hwang, C. S., Macconmara, M., \& Desai, D. M. (2019). Pediatric Abdominal Organ Transplantation. The Surgical Clinics of North America, 99(1), 73-85.https://doi.org/ 10.1016/j.suc.2018.09.006

İnci, F., \& Erdem, M. (2010). Bakım Verme Yükü Ölçeği’nin Türkçe’ye Uyarlanması Geçerlilik Ve Güvenilirliği. In Anadolu Hemşirelik ve Sağllk Bilimleri Dergisi (Vol. 11, pp. 85-95). Ataturk University. http://hdl.handle.net/11499/1903

Karahan, A., \& Islam, S. (2013). A Comparison Study about Caregiver Burden between Physically Disabled, Pediatric and Geriatric Patients. Journal of Marmara University Institute of Health Sciences, 1. https://doi.org/10.5455/musbed.20130210095507

Karayurt, Ö., Ordin, Y. S., Ünek, T., \& Astarcıŏlu, İ. (2015). Immunosuppressive Medication Adherence, Therapeutic Adherence, School Performance, Symptom Experience, and Depression Levels in Patients Having Undergone a Liver Transplant During Childhood. Experimental and Clinical Transplantation : Official Journal of the Middle East Society for Organ Transplantation, 13(3), 247-255. https://doi.org/10.6002/ect.2014.0150

Kardaş Özdemir, F., Şahin, A., Zümrüt, \& Küçük Alemdar, D. (2009). Kanserli çocuğu olan annelerin bakım verme yüklerinin belirlenmesi. Yeni Tıp Dergisi, 26(3), 153-158. https://app.trdizin.gov.tr/makale/T1RJMk5UVTE

Kärrfelt, H. M. E., Berg, U. B., \& Lindblad, F. I. E. (2000). Renal transplantation in children: Psychological and donationrelated aspects from the parental perspective. Pediatric Transplantation, 4(4), 305-312. https://doi.org/10.1034/j.13993046.2000.00135.x

Koçak, A., Aktaş, E. Ö., Şenol, E., Kaya, A., \& Bilgin, U. E. (2010). Ege Üniversitesi Tıp Fakültesi öğrencilerinin organ nakli ve bağışı hakkındaki bilgi düzeyi. Ege Tıp Dergisi, 49(3), 153-160. http://egetipdergisi.com.tr/tr/download/articlefile/350429

Koçyiğit, H. (1999). Kisa Form-36 (KF-36)'nm Turkce versiyonunun guvenilirligi ve gecerliligi. Ilaç ve Tedavi Dergisi, 12, 102-106.

Karaaslan, M., \& Çelebioğlu, A. (2020). Zihinsel Engelli Çocuğu Olan Ebeveynlerin Psikolojik Durumları ile Bakım Yükünün Değerlendirilmesi Evaluation of the Psychological Condition and Caregiver Burden of Parents who have Children with Mental Disabilities. https://doi.org/ 10.18301/rss.588

Sarwal, M. M., \& Bagga, A. (2013). Quality of life after organ transplantation in children. Current Opinion in Organ Transplantation, 18(5), 563-568. https://doi.org/10.1097/MOT.0b013e3283653550

Sundaram, S. S., Landgraf, J. M., Neighbors, K., Cohn, R. A., \& Alonso, E. M. (2007). Adolescent Health-Related Quality of Life Following Liver and Kidney Transplantation. American Journal of Transplantation, 7(4), 982-989.

https://doi.org/10.1111/j.1600-6143.2006.01722.x 
Thys, K., Schwering, K.-L., Siebelink, M., Dobbels, F., Borry, P., Schotsmans, P., \& Aujoulat, I. (2015). Psychosocial impact of pediatric living-donor kidney and liver transplantation on recipients, donors, and the family: a systematic review. Transplant International, 28(3), 270-280. https://doi.org/10.1111/tri.12481

Törüner, E., \& Büyükgönenç, L. (2012). Çocuk Să̆lı̆̆ı. Göktuğ Yayıncılık. 


\section{EXTENDED ABSTRACT}

Introduction: Organ transplantation is an accepted treatment method for children with end-stage organ failure. With advanced surgical techniques, medications used and studies on infection control, the survival time of children undergoing organ transplantation has increased. It is essential to provide the care needed by the child and the family during the transplantation process. This study was carried out to determine the quality of life and burden of care of parents of children undergone a transplantation procedure.

Materials and Methods: This descriptive study was carried out with the parents of pediatric patients admitted to organ transplantation unit in Şanlıurfa province. Organ transplantation unit at the university hospital has been in service since 2013 and organ transplantation is only performed on adults, referral procedures and some controls of pediatric patients are performed in this unit. The university is the only health centre in the province where the procedures of patients undergone transplantation surgery are performed. In the study, no sample selection was made and all pediatric patients registered were tried to be reached.

Parents of 22 pediatric patients residing in Şanlıurfa province and had an organ transplant in an external centre constitute the sample of the study. The data were obtained using the Descriptive Characteristics Questionnaire, Short Form - 36 Quality of Life Scale and Caregiving Burden Scale. The data were collected by the researcher in the room of the hospital's organ transplant outpatient clinic using a face-to-face interview technique with the parent of pediatric patients. Before the interview, the purpose of the study was explained to the parents and the interview lasted an average of 20 minutes. The data were evaluated using descriptive statistics, Mann Whitney U and Kruskal Wallis tests in the SPSS 22.0 program. To conduct the study, the permission of the ethics committee, institution and parents were obtained.

Findings: $59.1 \%$ of the children in the study were male, $4.5 \%$ were $0-3$ years old, $27.3 \%$ were $4-6$ years old, $31.8 \%$ were $7-12$ years old and $36.4 \%$ were between $13-18$ years old. It was determined that $91 \%$ of the transplanted organs in children was liver, $4.5 \%$ were the heart and ve $4.5 \%$ were kidney and that $54.5 \%$ were transplanted from living donors. The time after the transplant is between $1-5$ years in $77.3 \%, 6-10$ years in $22.7 \% .63 .6 \%$ of the mothers are in the $20-39$ age range, $36.4 \%$ are 40 or over. $63.6 \%$ of mothers and $9.1 \%$ of fathers are illiterate, $77.3 \%$ have four or more children and $40.9 \%$ have an average income level.

According to the total score averages of the parents obtained in the Caregiving Burden Scale, it was determined that their burden of care was $27.32 \pm 8.35$ mild to moderate, and their quality of life, physical and mental health score averages were $22.33 \pm 0.94,26.19 \pm 1.31$, respectively. According to the scale score averages of the caregivers from the caregiving burden scale, $77.3 \%$ of parents have a mild-moderate burden of care and $4.5 \%$ had moderate-severe burden of care.

It was determined that families scored $4.77 \pm 1.50$ from the lowest mental sub-dimension of the quality-of-life scale, and $25.90 \pm 4.78$ from the highest physical function sub-dimension from the quality-of-life scale. When looking at the distribution of the burden of care score averages of the descriptive characteristics in children who underwent organ transplantation, no significant difference was found in the average burden of care of the parents based on gender, donor, type of transplantation, duration of transplantation and mother's age $(\mathrm{p}>0.05)$.

It was determined that the gender of the child and income status of family affected the quality-of-life scores of the parents $(\mathrm{p}<0.05)$.

Discussion: In this study, the average burden of care of the parents of transplanted children was found to be $27.32 \pm 8.35$, mild and moderate. There is a limited number of studies in the literature on the burden of care of the parents of children who underwent organ transplantation. It was determined that the burden of care of parents of children with chronic diseases stated in the studies in the literature, was similar to the that of the parents of the children who underwent a transplantation procedure. In this study, the quality of life of parents was found as low. Similar results were found in studies evaluating the quality of life of parents of children who underwent organ transplantation (Sundaram ve ark. 2007; Dehghani ve ark. 2012).

\section{Conclusion and Suggestions:}

Parents of children with organ transplantation have a poor quality of life.

The burden of care of parents of children with organ transplantation is mild/moderate.

Monitoring the quality of life and burden of care of parents of transplanted children is recommended. 